\title{
The hidden cause of dysphagia - epiphrenic diverticulum and esophageal motility disorders
}

\author{
Aloysious Aravinthan MRCP, Marko Nikolic MRCP, Xiaomei Ouyang PhD, Young-Mee Lee MD
}

\begin{abstract}
A 65-year-old woman presented with slowly progressing dysphagia A of two to three years' duration. The patient's dysphagia was intermittent and was associated with solid food during the initial phase, but progressed to difficulty with swallowing liquids. During the few months before presentation, she also experienced heartburn, nausea and vomiting. She denied significant weight loss or anorexia. Her medical history was notable for cholecystectomy 11 years previously, and she was taking ranitidine.
\end{abstract}

Physical examination and routine laboratory investigations including complete blood count, renal and liver function tests were within the normal range. She underwent gastroscopy followed by a barium

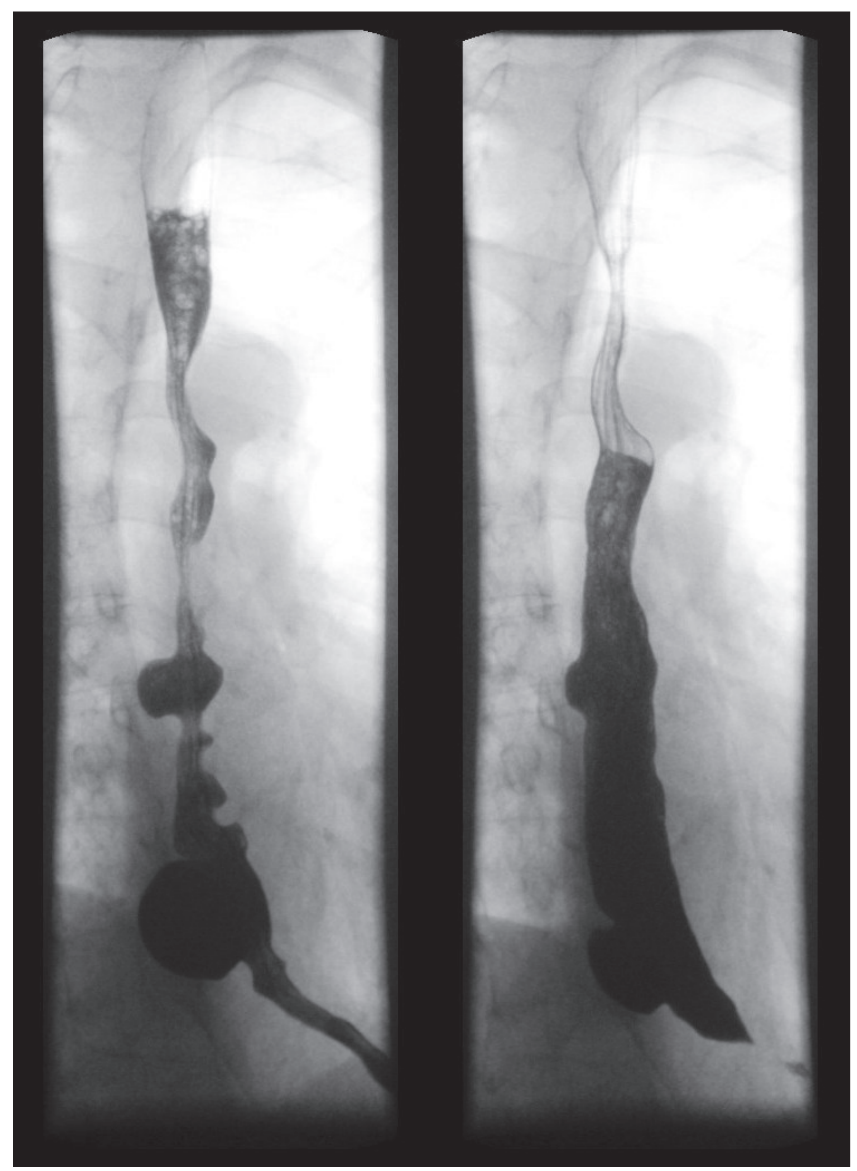

Figure 1) Barium swallow demonstrating an epiphrenic diverticulum and a midesophageal diverticulum swallow, which demonstrated an epiphrenic diverticulum and a midesophageal diverticulum (Figure 1).

Following barium swallow, she underwent esophageal manometry (Figure 2). This demonstrated simultaneous contraction in the esophageal body of normal amplitude and duration (Figure 2). The resting lower esophageal sphincter pressure was elevated $(49 \mathrm{mmHg})$, but the relaxation was complete (Figure 2), confirming an atypical variant achalasia. Gastroscopy also demonstrated epiphrenic diverticulum and a 'tight' gastroesophageal junction without a mucosal abnormality. The endoscope was passed through the gastroesophageal junction with a slight resistance.

\section{DISCUSSION}

Epiphrenic diverticulum is associated with concomitant esophageal motility disorders, most commonly achalasia $(1,2)$. Increased intraluminal pressure due to the primary esophageal motility disorder is suspected to be the underlying cause for the development of epiphrenic diverticulum, resulting in herniation of the mucosa and submucosa through the muscular layer.

Generally, symptoms correlate with esophageal dysmotility rather than with the size of the diverticulum (3). Treatment includes diverticulectomy and myomectomy, which can be performed laparoscopically (4). Due to her reluctance to consider surgical or endoscopic intervention, our patient was treated with the long-acting calcium channel blocker nifedipine. This achieved reasonable symptom control. However, medical therapy does not usually yield satisfactory results.

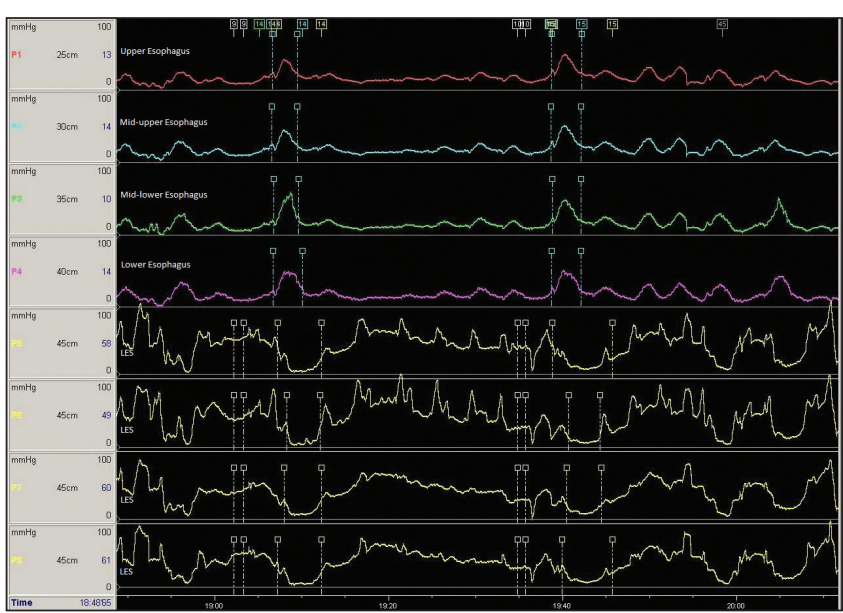

Figure 2) Esophageal manometry recording showing simultaneous contraction of the esophageal body of normal amplitude and raised lower esophageal sphincter pressure, but complete relaxation

Cambridge University Hospitals, Cambridge, United Kingdom

Correspondence: Dr Young-Mee Lee, Cambridge University Hospitals, Hills Road, Cambridge CB2 OQQ, United Kingdom.

Telephone 44-1223-336008, fax 44-1223-216111, e-mail youngmee1lee@aol.com

Received for publication November 4, 2011. Accepted November 17, 2011 
AUTHOR CONTRIBUTIONS: Each author was equally involved in preparing this article.

DISCLOSURES: The authors have no financial disclosures or conflicts of interest to declare.

\section{REFERENCES}

1. Nehra D, Lord RV, DeMeester TR, et al. Physiologic basis for the treatment of epiphrenic diverticulum. Ann Surg 2002;3:346-54.

2. Benacci JC, Deschamps C, Trastek VF, Allen MS, Daly RC, Pairolero PC. Epiphrenic diverticulum: Results of surgical treatment. Ann Thorac Surg 1993;55:1109-13.

3. Orringer MB. Epiphrenic diverticula: Fact and fable. Ann Thorac Surg 1993;55:1067-8.

4. Matthews BD, Nelms CD, Lohr CE, Harold KL, Kercher KW, Heniford BT. Minimally invasive management of epiphrenic esophageal diverticula. Am Surg 2003;69:465-70.

The Canadian Journal of Gastroenterology is now considering a limited number of submissions for IMAGE OF THE MONTH. These will be based on endoscopic, histological, radiological and/or patient images, which must be anonymous with no identifying features visible. The patient must consent to publication and the consent must be submitted with the manuscript. All manuscripts should be practical and relevant to clinical practice, and not simply a case report of an esoteric condition. The text should be brief, structured as CASE PRESENTATION and DISCUSSION, and not more than 700 words in length. A maximum of three images can be submitted and the number of references should not exceed five. The submission may be edited by our editorial team.

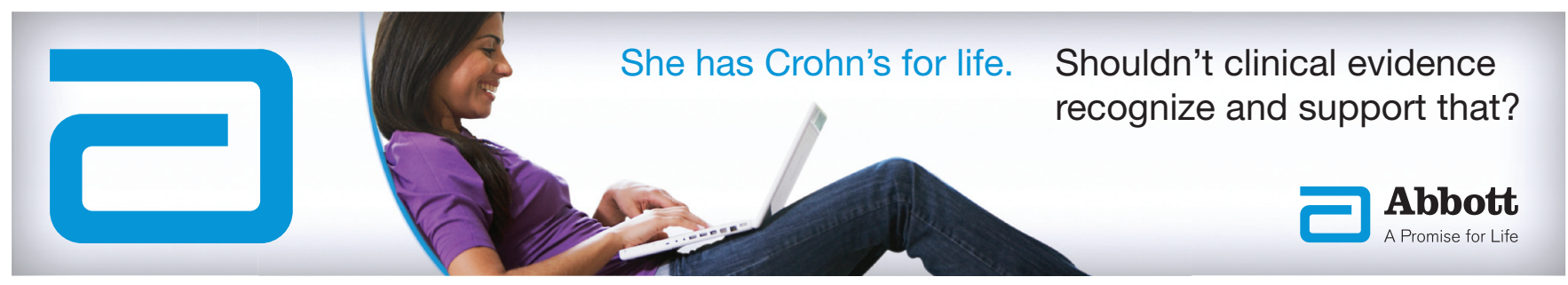




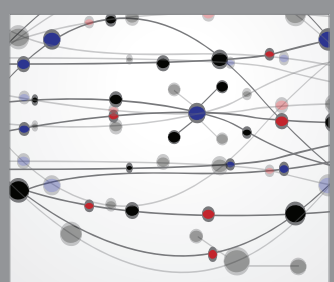

The Scientific World Journal
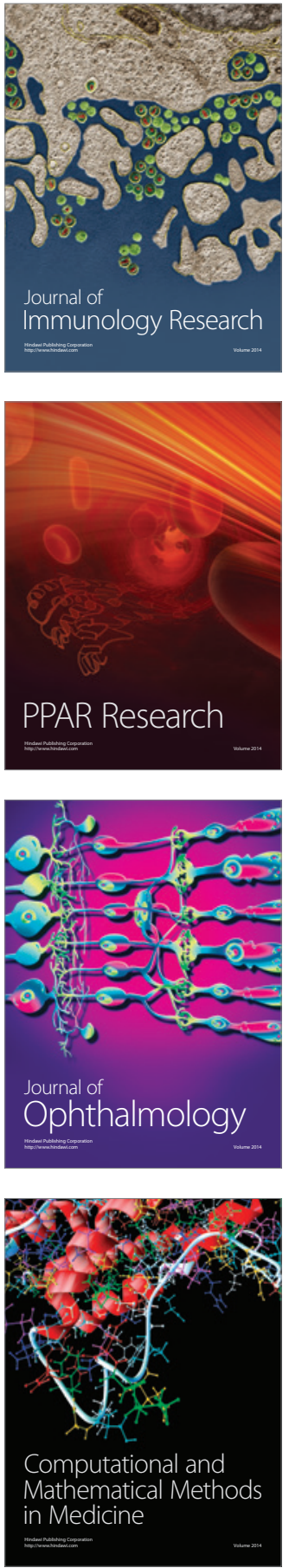

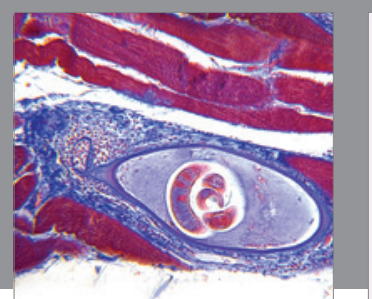

Gastroenterology Research and Practice

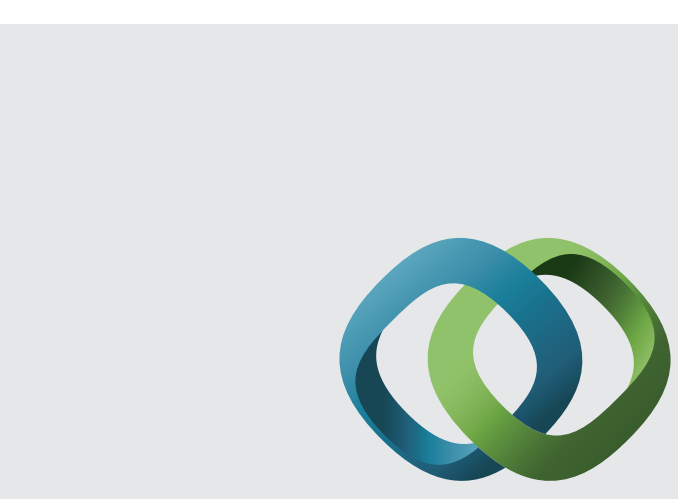

\section{Hindawi}

Submit your manuscripts at

http://www.hindawi.com
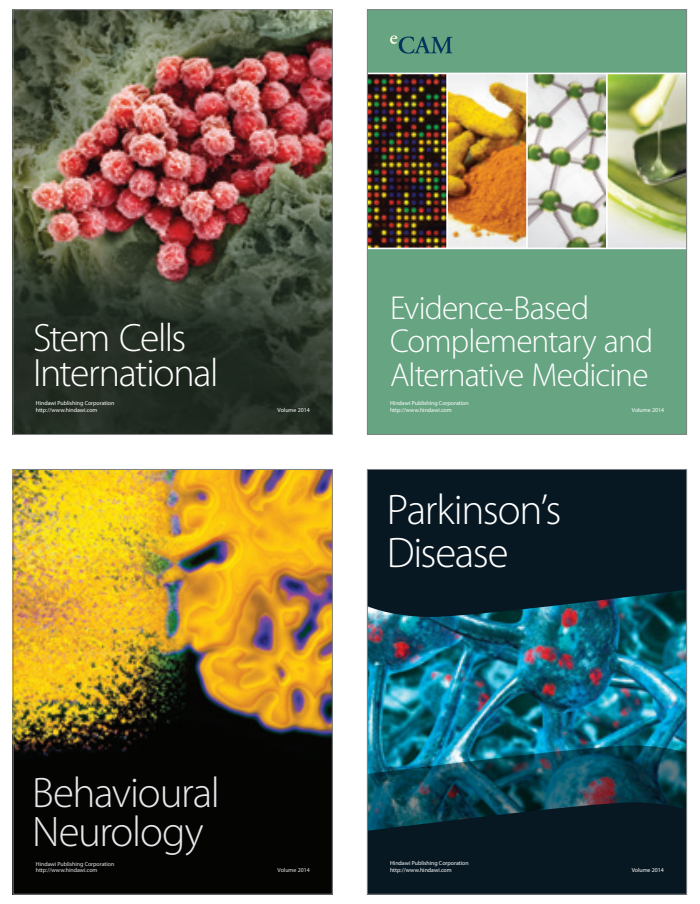
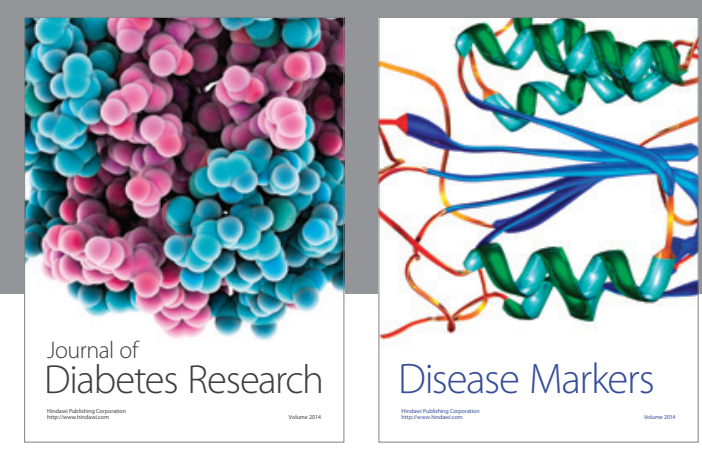

Disease Markers
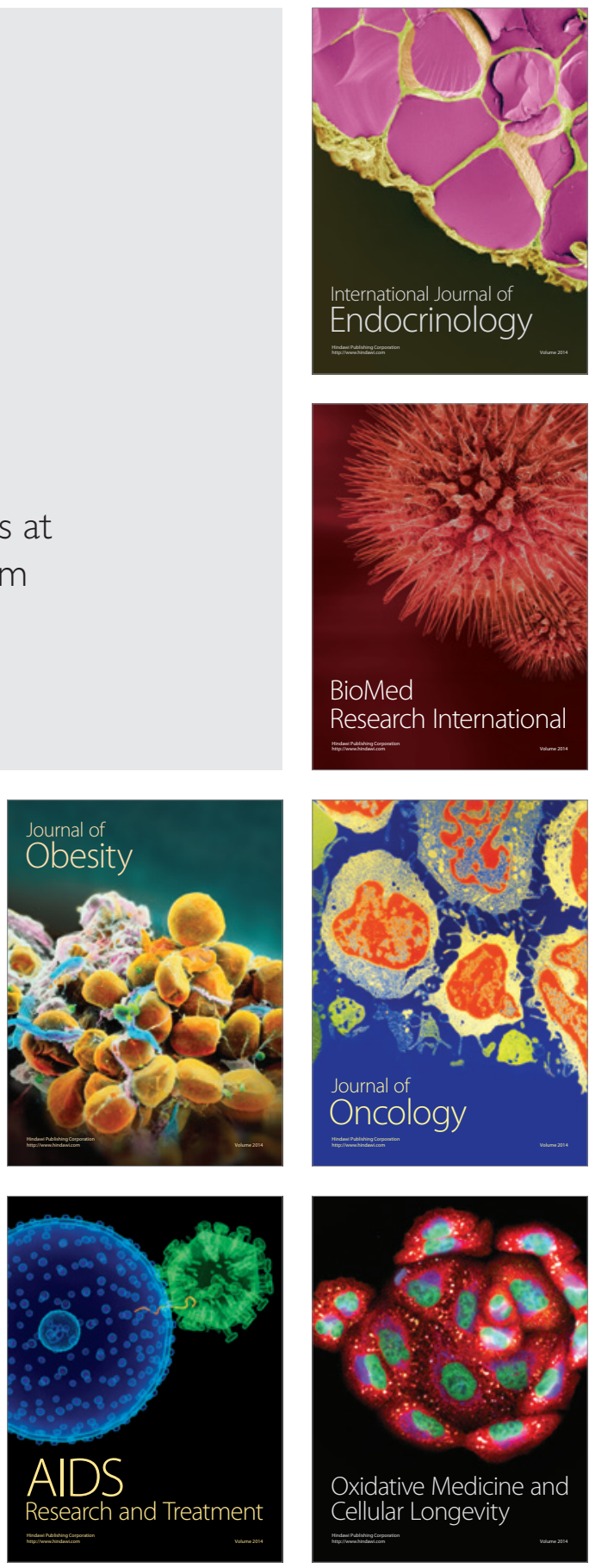